\title{
Legislative smoking bans for reducing exposure to secondhand smoke and smoking prevalence: Opportunities for Georgians
}

\author{
Steven S. Coughlin, PhD, ${ }^{1}$ Jennifer Anderson, MBA, RRT, AE-C, ${ }^{2}$ and Selina A. Smith, PhD, MDiv ${ }^{3}$
}

${ }^{1}$ Department of Epidemiology, Rollins School of Public Health, Emory University, Atlanta, GA; ${ }^{2}$ Director, Respiratory Care Service and Pulmonary Function Labs, Georgia Regents Medical Center, Augusta, GA; and ${ }^{3}$ Institute of Public and Preventive Health, and Department of Family Medicine, Medical College of Georgia, Georgia Regents University, Augusta, GA

\begin{abstract}
Background: Secondhand smoke, which is also referred to as environmental tobacco smoke and passive smoke, is a known human carcinogen. Secondhand smoke also causes disease and premature death in nonsmoking adults and children.
\end{abstract}

Methods: We summarize studies of secondhand smoke in public places before and after smoking bans, as well as studies of cardiovascular and respiratory disease before and after such bans.

Results: To protect the public from the harmful effects of secondhand smoke, smoke-free legislation is an effective public health measure. Smoking bans in public places, which have been implemented in many jurisdictions across the U.S. and in other countries, have the potential to influence social norms and reduce smoking behavior.

Conclusions: Through legislative smoking bans for reducing secondhand smoke exposure and smoking prevalence, opportunities exist to protect the health of Georgians and other Americans and to reduce health care costs. These opportunities include increasing the comprehensiveness of smoking bans in public places and ensuring adequate funding to quit line services.

Key Words: cancer; cardiovascular disease; environmental tobacco smoke; passive smoking; respiratory disease; secondhand smoke; smoke-free policy

\section{INTRODUCTION}

Cigarette smoking has been causally linked to numerous types of cancer (lung, mouth, nasal cavity, throat, laryngeal, esophageal, stomach, colon, liver, pancreatic, bladder, cervical, acute myeloid leukemia); cardiovascular disease (heart disease, stroke, aortic aneurysm); diabetes; rheumatoid arthritis; age-related macular degeneration; and respiratory illness (chronic bronchitis, emphysema) (National Cancer Institute, 2014). Smoking also contributes to respiratory infections (e.g., pneumonia) and, if a mother smokes while pregnant, to low birth weight and premature birth. Use of other tobacco products such as cigars or pipes also increases the risk of cancer. In the U.S., cigarette smoking causes about $90 \%$ of lung cancers. According to the Centers for Disease Control and Prevention (CDC), tobacco smoke is a toxic mixture of more than 7,000 chemicals, of which at least 70 are known to cause cancer. Individuals who smoke are 15-30 times more likely to develop lung cancer and die from lung cancer than people who do not smoke (National Cancer Institute, 2014). The risk of lung cancer increases with a greater number of years a person smokes and the number of cigarettes smoked each day.

Secondhand smoke, which is also known as environmental tobacco smoke and passive smoke, is classified as a human carcinogen by the U.S. Environmental Protection Agency, the U.S. Surgeon General, and the International Agency for Research on Cancer (EPA, 2011; DHHS, 2010; IARC, 2012). Inhaling secondhand smoke causes lung cancer in nonsmoking adults (DHHS, 2006), and living with a smoker increases a nonsmoker's chances of developing lung cancer by $20 \%$ to $30 \%$ (DHHS, 2006, 2010). Secondhand smoke causes disease and premature death in nonsmoking adults and children (DHHS, 2010). Exposure to secondhand smoke may increase the risk of heart disease by $25 \%$ to $30 \%$ (IOM, 2010) and the risk of stroke by $20 \%$ to $30 \%$ (DHHS, 2014). Pregnant women exposed to secondhand smoke are at risk of having a baby with low birth weight (DHHS, 2010). Children exposed to secondhand smoke are at an increased risk of ear infections, colds, pneumonia, and bronchitis, and worsening of asthma symptoms (National Cancer Institute, 2014; DHHS, 2010; Been et al. 2014). The economic costs of secondhand smoke are enormous, with communities of color bearing the greatest burden (Max et al. 2012).

Scientific evidence indicates that smoke-free legislation is an effective public health measure (Azagba, 2015; Apollonio \& Bero, 2009; Pickett et al. 2006). To protect the public from the harmful effects of secondhand smoke, smoking bans in public places have been implemented in many jurisdictions across the U.S. and in other countries. Such bans also have the potential to influence social norms and reduce smoking behavior (Callinan et al., 2010). These bans can be partial (e.g., hospitals, schools, airlines, trains, 
workplaces) or comprehensive (including bars, restaurants, and casinos).

In this commentary, we summarize studies of secondhand smoke in public places before and after implementation of smoking bans, as well as studies of cardiovascular disease before and after such bans. We also highlight opportunities to protect the health of Georgians and to reduce health care costs through legislative smoking bans for reducing smoking prevalence and exposure to secondhand smoke. Our review is based upon bibliographic searches in PubMed. We used the MeSH term for passive smoking to identify articles published in English in recent years. The search was not limited to words appearing in the title of an article. Information obtained from PubMed (title and topic of article, information in the abstract, geographic locality of a study, and key words) was used to determine whether or not to retain each article identified in this way. We examined key reports (e.g., those released by the Institute of Medicine) and reviewed the references of reports and review articles.

\section{Studies Of Secondhand Smoke In Public Places Before And After Smoking Bans}

Callinan et al. (2010) systematically reviewed the literature on smoking bans in public places and included 50 studies in their review. Of these, 31 studies reported exposure to secondhand smoke, and 19 studies assessed exposure by use of biomarkers. There was consistent evidence that smoking bans reduced exposure to secondhand smoke in workplaces, restaurants, pubs, and other public places. For hospitality workers, there was a greater reduction in exposure to secondhand smoke relative to the general population. After the bans, there was also a reduction in hospital admissions for cardiac events (acute coronary syndrome) (Callinan et al., 2010).

In Boston, Massachusetts, Repace et al. (2006) evaluated the air quality benefits of a smoke-free workplace law by measuring air pollution from secondhand smoke in 7 pubs before and after the law was implemented, comparing actual ventilation practices to engineering society (ASHRAE) recommendations and assessing secondhand smoke levels using health and comfort indices. The researchers measured respirable particle (RSP) air pollution and particulate polycyclic aromatic hydrocarbons (PPAH), in the pubs and outdoors, and assessed ventilation rates from carbon dioxide concentrations (Repace et al., 2006). To assess health risks, they compared RSP air pollution to the federal Air Quality Index (AQI) and the National Ambient Air Quality Standard (NAAQS) and assessed odor and irritation levels by use of published secondhand smoke-RSP thresholds (Repace et al., 2006). Pre-smoking-ban RSP levels in the pubs averaged $179 \mu \mathrm{g} / \mathrm{m}^{3}, 23$ times higher than post-ban levels, which averaged $7.7 \mu \mathrm{g} / \mathrm{m}^{3}$, and exceeding the NAAQS for fine particle pollution (particulate matter $<2.5$ microns in diameter, $\operatorname{PM(2.5)~by~less~than~4-fold~(Repace~et~al.,~2006).~}$ Pre-smoking ban levels of fine particle air pollution in the pubs were in the 'unhealthy' to 'hazardous' range of the AQI. Pre-ban indoor carcinogenic PPAH averaged 61.7 $\mathrm{ng} / \mathrm{m}^{3}$, nearly 10 times higher than post-ban levels of 6.32 $\mathrm{ng} / \mathrm{m}^{3}$. Post-ban particulate air pollution levels were generally in the 'good' AQI range, and post-ban carcinogen levels in the pubs were lower than outdoors. The authors noted that, prior to the ban, pub ventilation rates per occupant were within ASHRAE design parameters for the control of carbon dioxide levels for the number of occupants present, but they failed to control secondhand smoke carcinogens or RSP (Repace et al., 2006). Secondhand smoke odor and irritation sensory thresholds of nonsmokers were exceeded. Post-ban air pollution measurements showed $90 \%$ and $95 \%$ reductions in PPAH and RSP, respectively, and the values differed little from outdoor concentrations. In a separate study in Delaware, Repace (2004) measured RSP air pollution and particulate polycyclic aromatic hydrocarbons (PPAH) in a casino, six bars, and a pool hall before and after a smoking ban. Prior to the ban, secondhand smoke contributed $90 \%$ to $95 \%$ of the RSP air pollution during smoking, and $85 \%$ to $95 \%$ of the carcinogenic PPAH, which exceeded levels of these contaminants on major highways and polluted city streets (Repace, 2004).

Semple et al. (2007) studied the effect of smoke-free legislation on occupational exposure of bar workers to secondhand smoke. A total of 371 bar workers were recruited from 72 bars in three Scottish cities (Aberdeen, Glasgow, and Edinburgh) and small towns in two rural regions (Borders and Aberdeenshire). Prior to the introduction of the smoke-free legislation, the researchers visited participants in their place of work and collected saliva samples for the measurement of cotinine, together with details on work patterns, self-reported exposure to secondhand smoke at work and non-work settings, and smoking history (Semple et al., 2007). This was repeated at 2 months post-legislation and again one year later. They also collected, at baseline and at 2 months post-legislation, data on full-shift personal exposure from a small number of Aberdeen bar workers using a personal aerosol monitor for fine particulate matter $[\mathrm{PM}(2.5)]$. The salivary cotinine levels recorded for non-smokers fell from a geometric mean of $2.94 \mathrm{ng} / \mathrm{ml}$ prior to introduction of the legislation to 0.41 $\mathrm{ng} / \mathrm{ml}$ at the 1-year follow-up (Semple et al., 2007). For non-smokers, paired data showed a reduction in cotinine levels of $89 \%$ [95\% confidence interval (CI) 85-92\%]. For the entire cohort, the duration of workplace exposure to secondhand smoke within the last 7 days fell from 28.5 to 0.83 hours (Semple et al., 2007). Smokers also demonstrated reductions in their salivary cotinine levels of $12 \%$ (95\% CI 3-20\%). In a small sub-sample of bar workers, full-shift personal exposure to $\operatorname{PM(2.5),~a~marker~}$ of secondhand smoke concentrations, showed average reductions of $86 \%$ between baseline and 2 months after implementation of the legislation (Semple et al., 2007). In a more recent study, (Semple et al., 2010) evaluated the effect of smoke-free legislation on air levels of $\mathrm{PM}(2.5)$ in 106 randomly selected bars in Scotland, England, and Wales. $\mathrm{PM}(2.5)$ concentrations were measured covertly for 30-min periods before smoke-free legislation was introduced, again at 1-2 months post-ban (except Wales), and then at 12months post-baseline (except Scotland) (Semple et al., 2010). In Scotland and England, overt measurements were accomplished to assess personal exposure of full-shift bar workers to $\mathrm{PM}(2.5)$. Following introduction of the 
legislation, those exposed in all three areas experienced a substantial reduction in $\operatorname{PM}(2.5)$ concentrations, with the median reduction ranging from 84 to $93 \%$ (Semple et al., 2010). Reductions in personal exposure reductions were also within this range. Prior to legislation, $\operatorname{PM}(2.5)$ concentrations within bars across the United Kingdom were higher than the $65 \mu \mathrm{g} / \mathrm{m}^{3}$ 'unhealthy' threshold for outdoor air quality as set by the US Environmental Protection Agency. Legislation in all three areas produced improvements in indoor air quality that were consistent with results of other international studies (Semple et al., 2010). In Canada, restricting smoking in restaurant and bar patios reduced self-reported exposure to secondhand smoke (Azagba, 2015). Naiman et al. (2011) examined whether smoking bans in Canada reduced exposure to secondhand smoke in public places. The researchers used Canadian Community Health Survey data to obtain rates of exposure in 15 Ontario municipalities. Across all of the municipalities, secondhand smoke exposure in public places decreased by $4.7 \%$, and workplace exposure decreased by $2.3 \%$ following the introduction of public smoking bans (Naiman et al., 2011). Implementation of a full smoking ban was associated with the largest decreases in secondhand smoke exposure; partial bans and changes in existing bans had inconsistent effects (Naiman et al., 2011).

In Savannah, Georgia, among restaurants and bars that allowed smoking prior to passage of a smoke-free workplace ordinance, the indoor air pollution decreased by 93\%, a decline in the mean $\operatorname{PM}(2.5)$ from 181 to 12 , after the smoking ban (Georgia Department of Public Health, 2012). The decrease in indoor air pollution moved from the 'very unhealthy' range to the 'good' range on the US Environmental Protection Agency's AQI.

Similar findings have been obtained in studies of secondhand smoke before and after public smoking bans in New Zealand, South Korea, China, France, Ireland, and other countries (Fong et al., 2006; Fong et al., 2013).

\section{Studies Of Cardiovascular And Respiratory Disease Before And After Smoking Bans}

Following the enactment of smoke-free laws, there have been reductions in hospitalizations for acute coronary events. Jones et al. (2014) conducted a systematic review and meta-analysis of epidemiologic studies that examined how smoking bans in public places relate to the risk of acute coronary events. Thirty-one studies that provided estimates for 47 locations were included. Following the enactment of smoke-free legislation, there was a $12 \%$ reduction in hospitalizations for acute coronary events (pooled relative risk $[\mathrm{RR}]=0.88,95 \% \mathrm{CI}$ 0.85-0.90). The cardiovascular benefits were greater in locations with comprehensive legislation than in those with partial bans (Jones et al., 2014). Tan and Glantz (2012) conducted a meta-analysis of 45 studies to examine the relationship between smoke-free legislation and hospital admissions or deaths from cardiac, cerebrovascular, and respiratory diseases. Comprehensive smoke-free legislation was associated with lower rates of hospital admissions (or deaths) for all 4 diagnostic groups: coronary events (pooled $\mathrm{RR}=0.848,95 \%$ CI 0.816-0.881), other heart disease (pooled $\mathrm{RR}=0.610$, 95\% CI 0.440 0.847), cerebrovascular accidents (pooled RR 0.840, 95\% CI 0.753-0.936), and respiratory disease (pooled $\mathrm{RR}=$ 0.760 , 95\% CI 0.682-0.846). More comprehensive laws (covering workplaces, restaurants, and bars vs. workplaces only) were associated with larger changes in risk (Tan \& Glantz, 2012). Barr et al. (2012) examined hospital admission rates for acute myocardial infarction (AMI) among 6 million Medicare enrollees aged 65 years or older in 387 U.S. counties (across 9 U.S. states) that enacted comprehensive smoking bans. Smoking bans were associated with a significant decrease in admissions for AMI in the 12 months following the ban.

\section{Opportunities To Protect The Health Of Georgians Through Legislative Smoking Bans}

Tobacco use remains the leading cause of preventable death and disease in Georgia and across the U.S. To address this toll, the American Lung Association and its partners have committed to three ambitious goals: 1) reduce smoking rates, currently at about 18 percent, to less than 10 percent by 2024 ; 2) protect all Americans from secondhand smoke by 2019; and 3) ultimately eliminate the death and disease caused by tobacco use (American Lung Association, 2015). In Georgia, the American Lung Association recognizes that these goals will be met only if the following three actions are taken by elected officials: 1) substantially increase the price of tobacco products, including on electronic smoking devices; 2) increase the number of local comprehensive laws relating to smoke-free air; and 3) increase funding of tobacco control programs. In 2014, Georgia's State Board of Regents passed a measure requiring all 31 state college and university campuses to be tobacco-free, effective October 1, 2014. The measure includes all forms of tobacco. Another step forward was coverage of smoking cessation counseling by telephone for Georgia Medicaid recipients (American Lung Association, 2015).

The Department of Public Health funds the Georgia Tobacco Quit Line, which is a free, confidential service available to assist Georgians with quitting smoking and all other forms of tobacco. The toll-free line is: 1-877-270-STOP (877-270-7867) (English), 1-877-2NO-FUME (877-266-3863) (Spanish), or 1-877-777-6534 (hearing impaired). The hours of operation are 24 hours a day, 7 days a week. Callers receive free quitting tips/techniques and support. The Quit Line eliminates barriers of traditional cessation classes, such as waiting for a class to be held or having to drive to a location in order to be in a class, and provides easy access for people who live in rural or remote areas. Any tobacco user 13 years or older who lives in Georgia is eligible to receive Quit Line services. Nevertheless, Georgia's state tobacco prevention program and Quit Line are run on limited state funding, and Georgia ranks in the bottom tier of states in providing funding to reduce tobacco use (American Lung Association, 2015).

Georgia has the lowest tobacco tax of all surrounding states, and, at 37 cents per pack, the tax is among the lowest in the country. According to the American Lung Association, 
Georgia has an opportunity to improve public health and to enhance state revenues by increasing the cigarette tax by $\$ 1.25$ per pack. This will reduce smoking, prevent youngsters from starting, and provide a new source of funding that can benefit the state's tobacco prevention program. Information about smoking and smoking-related deaths in Georgia is shown in Table 1.

\begin{tabular}{|l|c|}
\hline Table 1: Smoking Facts and Figures for the state of Georgia, U.S. \\
\hline Economic Cost Due to Smoking & $\$ 5,681,925,000$ \\
\hline Adult Smoking Rate & $18.80 \%$ \\
\hline High School Smoking Rate & $12.80 \%$ \\
\hline Middle School Smoking Rate & $5.80 \%$ \\
\hline Smoking Attributable Deaths & 10,546 \\
\hline Smoking Attributable Lung Cancer Deaths & 3,437 \\
\hline Smoking Attributable Respiratory Disease Deaths & 2,660 \\
\hline
\end{tabular}

${ }^{1}$ Data provided by the American Lung Association. The adult smoking rate is taken from CDC's 2013 Behavioral Risk Factor Surveillance System; the high school smoking rate is taken from the 2013 Youth Risk Behavior Surveillance System; and the middle school smoking rate is taken from the 2011 Youth Tobacco Survey.

The Georgia Smoke Free Air Act of 2005 banned smoking statewide in all enclosed workplaces in Georgia, except as otherwise designated. The Act exempts designated smoking areas in non-work areas of businesses that are separately ventilated, bars and restaurants where persons under 18 years of age are not employed or permitted to enter, separately enclosed smoking rooms in any bar or restaurant, private residences not used as healthcare or child daycare facilities, hotel/motel rooms designated as smoking rooms, retail tobacco stores, nursing homes, outdoor areas, designated areas in international airports, workplaces of a tobacco manufacturer or other tobacco business, privately owned meeting and assembly rooms during private functions where persons under 18 are not allowed, and areas of private places of employment (other than medical facilities) that are open to the general public by appointment only. Atlanta has no smoking ban covering workplaces and/or restaurants and/or bars but does prohibit smoking in parks. Local governments may regulate smoking more strictly than the state. Municipalities in Georgia that have enacted smoke free laws that are stronger than the Georgia Smoke Free Air Act are shown in Tables 2 and 3.

Table 2: Georgia Municipalities that have Enacted Smoke Free Laws Stronger Than the Georgia Smoke Free Law of 2005

\begin{tabular}{|l|l|}
\hline Municipality & \multicolumn{1}{|c|}{ Legislation } \\
\hline Athens & smoking banned in bars and restaurants, but not other workplaces \\
\hline Buena Vista & smoking banned in all enclosed workplaces, including bars and restaurants \\
\hline Chatham County & smoking banned in all enclosed workplaces, including bars, private clubs, restaurants, and retail tobacco stores \\
\hline Effingham County & smoking banned in bars and restaurants, but not other workplaces \\
\hline Gainesville & smoking banned in bars and restaurants, but not other workplaces \\
\hline Morrow & smoking banned in all enclosed workplaces, including bars and restaurants \\
\hline Pooler & smoking banned in all enclosed workplaces, including bars and restaurants \\
\hline Savannah & smoking banned in bars and restaurants and in service queues \\
\hline Snellville & smoking banned in bars and restaurants, but not other workplaces \\
\hline Tift County & smoking banned in bars and restaurants, but not other workplaces \\
\hline
\end{tabular}




\begin{tabular}{|c|c|}
\hline Municipality & Legislation \\
\hline Berkeley Lake & smoking banned in all enclosed workplaces, including restaurants but exempting freestanding bars \\
\hline Columbia County & smoking banned in all enclosed workplaces, including restaurants but exempting freestanding bars \\
\hline Cordele & smoking banned in all enclosed workplaces, except bars and restaurants \\
\hline Decatur & smoking banned in all enclosed workplaces, including restaurants but exempting freestanding bars \\
\hline DeKalb County & smoking banned in all enclosed workplaces, except bars and restaurants \\
\hline Douglas & smoking banned in all enclosed workplaces, including restaurants but exempting freestanding bars \\
\hline Douglas County & smoking banned in all enclosed workplaces, including restaurants but exempting freestanding bars \\
\hline Douglasville & smoking banned in all enclosed workplaces, except bars and restaurants \\
\hline Dunwoody & smoking banned in all enclosed workplaces, except bars and restaurants \\
\hline Loganville & smoking banned in all enclosed workplaces, including restaurants but exempting freestanding bars \\
\hline Madison & smoking banned in all restaurants, but not in freestanding bars or all other enclosed workplaces \\
\hline Peachtree City & smoking banned in all restaurants, but not in freestanding bars or all other enclosed workplaces \\
\hline Tifton & smoking banned in all restaurants, but not in freestanding bars or all other enclosed workplaces \\
\hline Valdosta & smoking banned in all enclosed workplaces, including restaurants but exempting freestanding bars \\
\hline
\end{tabular}

\section{DISCUSSION}

To protect people from exposure to secondhand smoke, legislation banning smoking in indoor public places and workplaces is being implemented in various locations worldwide. Smoking bans in public places go hand-in-hand with workplace interventions aimed at helping people to stop smoking. These include smoking bans in hospitals, schools, and other occupational settings; group therapy sessions; individual counseling; quit lines; self-help materials; and nicotine replacement therapy (Moher et al., 2005). Smoking bans in public places and in the workplace are part of comprehensive tobacco control programs that focus on combatting smoking initiation and cessation. Other evidence-based interventions include restrictions on underage smoking, increasing the unit price of tobacco products, reducing out-of-pocket costs for evidence-based cessation treatments, and cessation treatment by health care providers. Restrictions on tobacco advertising are also helpful.

The U.S. Public Health Service Clinical Practice Guideline for the Treatment of Tobacco Dependence provides best practice standards for treating tobacco dependence (Fiore et al., 2009). Techniques stemming from behaviorally based counseling models, including motivational enhancement and skills training, are effective for smoking cessation (Gritz et al., 2006). The provision of social support is also helpful. Pharmacotherapies for smoking cessation include nicotine replacement therapy (nicotine patch, gum, inhaler, spray, and lozenge) and the antidepressant, bupropion. A variety of evidence-based public health and clinical interventions are available to help people quit smoking, as systematically reviewed by the Guide to Community Preventive Services (http://www.thecommunityguide.org/index.html) and by the U.S. Preventive Services Taskforce (http://www.uspreventiveservicestaskforce.org/recommenda tions.htm). Training health professionals in regard to smoking cessation increases delivery of these services and increases quit rates (Hillen et al., 2011). Resources that are available to train providers include pocket guides, online material, and the 5 A's system of counseling patients to stop using tobacco (Ask, Advise, Assess, Assist, and Arrange) (Fiore et al., 2009). The latter strategy includes: 1) identifying and documenting tobacco use for every patient at every visit, 2) strongly urging every tobacco user to quit, 3) determining the willingness of the tobacco user to make a quit attempt, 4) using counseling and pharmacotherapy to aid patients in quitting, and 5) scheduling follow-up contact (Fiore et al., 2009; Gritz et al., 2006). Potential barriers to proper provider education include overloaded curricula, low priority of tobacco control content, and negative attitudes toward tobacco control (Duffy et al., 2012).

In conclusion, smoke-free legislation is an effective measure to protect the public from the harmful effects of secondhand smoke. Legislative smoking bans also have the potential to influence social norms and reduce smoking behavior, thereby reducing exposure to secondhand smoke exposure and smoking prevalence (Hyland et al. 2012). Opportunities to protect the health of Georgians and other Americans and to reduce health care costs include increasing the comprehensiveness of smoking bans in public places and ensuring adequate funding to the Quit Line services that are offered free to Georgia residents by the Georgia Department of Public Health.

\section{Acknowledgements}

This work was funded by the National Cancer Institute (1R01CA166785-01). 


\section{References}

Apollonio, D.E. \& Bero, L.A. (2009) Evidence and argument in policymaking: development of workplace smoking legislation. BMC Public Health, 9, 189.

Azagba, S. (2015) Effect of smoke-free patio policy of restaurants and bars on exposure to second-hand smoke. Prev Med, 76, 74-8.

American Lung Association (2015). State of Tobacco Control Available at: http://www.stateoftobaccocontrol.org/stategrades/georgia/highlights.html [Accessed on May 15, 2015].

Bar, C.D., Diez, D.M., Wang, Y., et al. (2012) Comprehensive smoking bans and acute myocardial infarction among Medicare enrollees in 387 US counties: 1999-2008.

Am J Epidemiol, 176, 642-8, Epub 2012 Sep 17.

Been, J.V., Nurmatov, U.B., Cox, B., et al. (2014) Effect of smoke-free legislation on perinatal and child health: a systematic review and meta-analysis. Lancet, 383, 1549-60.

Callinan, J.E., Clarke, A., Doherty, K., Kelleher, C. (2010) Legislative smoking ban $\mathrm{s}$ for reducing secondhand smoke exposure, smoking prevalence and tobacco consumption. Cochrane Database Syst Rev, 14, CD005992. doi: 10.1002/14651858.CD005992.pub2.

Department of Health and Human Services (2014). The Health Consequences of Smoking-50 Years of Progress: A Report of the Surgeon General, 2014. Atlanta, GA: U.S. Department of Health and Human Services, Centers for Disease Control and Prevention, National Center for Chronic Disease Prevention and Health Promotion, Office on Smoking and Health.

Department of Health and Human Services (2010). How Tobacco Smoke Causes Disease: The Biology and Behavioral Basis for Smoking-Attributable Disease: A Report of the Surgeon General. Atlanta, GA: U.S. Department of Health and Human Services, Centers for Disease Control and Prevention, National Center for Chronic Disease Prevention and Health Promotion, Office on Smoking and Health.

Department of Health and Human Services (2006). The Health Consequences of Involuntary Exposure to Tobacco Smoke: A Report of the Surgeon General. Rockville, MD: U.S. Department of Health and Human Services, Centers for Disease Control and Prevention, Coordinating Center for Health Promotion, National Center for Chronic Disease Prevention and Health Promotion, Office on Smoking and Health.

Duffy, S.A., Louzon, S.A., Gritz, E.R. (2012) Why do cancer patients smoke and what can providers do about it? Community Oncol, 9, 344-52.

Environmental Protection Agency (November 30, 2011). Health Effects of Exposure to Secondhand Smoke. Available at: http://www.epa.gov/smokefree/healtheffects.html [Accessed May 15, 2015].

Fiore, M.C., Jaen, C.R., Baker, T.B., et al. (2009) Treating tobacco use and dependence: 2008 update. Clinical Practice Guideline. Rockville, MD: U.S. Department of Health and Human Services, Public health Service.

Fong, G.T., Hyland, A., Borland, R, et al. (2006) Reductions in tobacco smoke pollution and increases in support for smoke-free public places following the implementation of comprehensive smoke-free workplace legislation in the Republic of Ireland: findings from the ITC Ireland/UK Survey. Tob Control, Suppl 3, iii51-8.

Fong, G.T., Craig, L.V., Guignard, R, et al. (2013) Evaluation of the smoking ban in public places in France one year and five years after its implementation: Findings from the ITC France survey. Bull Epidemiol Hebd (Paris), 20, 217-23.

Georgia Department of Public Health (2012). Savannah SmokeFree Ordinance Improves Indoor Air Quality. Available at: http://www. http://dph.georgia.gov/blog/2013-09-05/savannahsmoke-free-ordinance-improves-indoor-air-quality [Accessed May 27, 2015].
Gritz, E.R., Fingeret, M.C., Vidrine, D.J., et al. (2006) Successes and failures of the teachable moment. Smoking cessation in cancer patients. Cancer, 106, 17-27.

Hillen, M.A., de Haes, H.C., Smets, E.M. (2011) Cancer patients' trust in their physician - a review. Psychooncology, 20, 227-41.

Hyland, A., Barnoya, J. \& Corral, J.E. (2012) Smoke-free air policies: past, present and future. Tob Control, 21, 154.

Institute of Medicine (2010). Committee on Secondhand Smoke Exposure and Acute Coronary Events. Secondhand Smoke Exposure and Cardiovascular Effects: Making Sense of the Evidence. Washington, DC: National Academy of Science.

International Agency for Research on Cancer (2012). Second-hand Tobacco Smoke, and Smokeless Tobacco. Lyon, France: IARC Monographs on the Evaluation of Carcinogenic Risks to Humans, Vol. 100E.

Jones, M.R., Barnova, J., Stranges, S., et al. (2014) Cardiovascular events following smoke-free legislations: an updated systematic review and meta-analysis. Curr Environ Health Rep, 1, 239-49.

Max, W., Sung, H., \& Shi, Y. (2012) Deaths from Secondhand Smoke Exposure in the United States: Economic Implications. Am J Public Health, 102, 2173-80.

Moher, M., Hey, K., Lancaster, T. (2005) Workplace interventions for smoking cessation. Cochrane Database Syst Rev, 18, CD003440.

Naiman, A.B., Glazier, R.H., Moineddin, R. (2011) Is there an impact of public smoking bans on self-reported smoking status and exposure to secondhand smoke? BMC Public Health, 11, 146.

National Cancer Institute (2014). Harms of cigarette smoking and health benefits of quitting. Available at: http://www.cancer.gov/cancertopics/causesprevention/risk/tobacco/cessation-fact-sheet [Accessed May 14, 2015].

Pickett, M. S., Schober, S. E., Brody, D. J., et al. (2006) Smokefree laws and secondhand smoke exposure in US non-smoking adults, 1999-2002. Tob Control, 15, 302.

Repace, J. (2004) Respirable particles and carcinogens in the air of Delaware hospitality venues before and after a smoking ban. J Occup Environ Med, 46, 887-905.

Repace, J.L., Hyde, J.N., Brugge, D. (2006) Air pollution in Boston bars before and after smoking ban. BMC Public Health, 6, 266.

Semple, S., Maccalman, L., Naji, A.A., et al. (2007) Bar workers' exposure to second-hand smoke: the effect of Scottish smokefree legislation on occupational exposure. Ann Occup Hyg 51, 571-80.

Semple, S., van Tongeren, M., Galea, K.S., et al. (2010) UK smoke-free legislation: changes in PM2.5 concentrations in bars in Scotland, England, and Wales. Ann Occup Hyg, 54, 272-80.

Tan, C.E., Glantz, S.A. (2012) Association between smoke-free legislation and hospitalizations for cardiac, cerebrovascular, and respiratory diseases: a meta-analysis. Circulation, 126, 2177-83. 